\title{
Oxidative Stress and Antioxidant Status in Vitiligo Patients
}

\section{Naushin Haider ${ }^{1}$, Mohammad Safiqul Islam², Abdullah Al Maruf ${ }^{2}$, Md. Hasanuzzaman Shohag ${ }^{2}$, Rubaiya Ali ${ }^{3}$, G.K.M. Mustafizur Rahman ${ }^{4}$, and Abul Hasnat ${ }^{2}$}

\author{
${ }^{1}$ Department of Pharmacy, University of Asia Pacific, Dhanmondi, Dhaka-1209, Bangladesh. \\ ${ }^{2}$ Department of Clinical Pharmacy and Pharmacology, University of Dhaka, Dhaka-1000, Bangladesh. \\ ${ }^{3}$ Department of Dermatology, Bangabandhu Sheikh Mujib Medical University, Dhaka-1000, Bangladesh. \\ ${ }^{4}$ Department of Soil Science, Faculty of Agriculture, Bangabandhu Sheikh Mujibur Rahman Agricultural \\ University, Bangladesh.
}

\begin{abstract}
Vitiligo is a common pigmentary disorder characterized by depigmented patches or macules caused by the destruction of melanocytes. The pathogenetic mechanisms involved in vitiligo have not been completely clarified. Oxidative stress and reduced circulating antioxidants could be important phenomena in the pathophysiology of vitiligo. We measured serum malondialdehyde (MDA) as an indicator of oxidative stress and serum zinc and vitamin $\mathrm{C}$ to check antioxidant status in thirty Vitiligo patients. Thirty healthy control subjects were also recruited by matching the socio-demographic status to that of the patients. Blood samples were analyzed for determining the serum levels of Zn (by atomic absorption spectroscopy), Vitamin C and MDA (by UV-VIS spectroscopy). Serum level of MDA increased in vitiligo patients significantly $(p<0.05)$ in the present study, where as serum level of $\mathrm{Zn}$ increased and serum Vit-C decreased in patients compared to control but the changes were not statistically significant $(p>0.05)$. Our study reveals the presence of an imbalance in the oxidant/antioxidant system in vitiligo patients which supports a free radical-mediated damage in the pathogenesis of vitiligo.
\end{abstract}

Key words: Vitiligo, Oxidative stress, Antioxidant status, MDA, Vitamin C, Zinc

\section{INTRODUCTION}

Vitiligo is a common and often heritable, acquired pigmentation disorder in which melanocytes in the skin, mucous membranes and the retina are destroyed. ${ }^{1}$ As a result depigmented patch appear on different parts of the body. The incidence worldwide is between $0.1 \%$ and $8.8 \%{ }^{2}$ This disorder affects all age groups, all races and both sexes. ${ }^{3}$ Vitiligo generally appears in one of the three patterns; focal, segmental and generalized. ${ }^{1}$ Vitiligo has major impact on quality of life of patients, many of whom experience distress and stigmatization. ${ }^{1}$

Correspondence to:

Abul Hasnat

Tel: +880-2-9661920-73 Extn. 8164; Fax: +880-2-8615583

E-mail: ahasnat99@yahoo.com

Dhaka Univ. J. Pharm. Sci. 9(2): 103-108, 2010 (December)
Exact etiology of vitiligo is not known. Autoimmune hypothesis is the most widely accepted since autoantibodies to melanocytes and tyrosinase have been demonstrated and also due to the association of vitiligo with other autoimmune diseases. ${ }^{4}$ A defective antioxidant defense is also postulated to lead to the unhindered cytotoxic action of reactive oxygen species such as superoxide anion, hydroxyl radical, etc. ${ }^{5}$ After formation, these highly reactive free radicals can start a chain reaction and bring about lipid peroxidation producing lipid peroxides and lipoxides, whose further decomposition yields a variety of end products, including malondialdehyde (MDA). ${ }^{5}$ These decomposition products can cause damage to cell membrane or DNA leading to cytotoxicity, 
mutagenicity and cell death. ${ }^{5}$ These reactive oxygen species are generated following ultraviolet rays induced damage to the epidermis. They are also cytotoxic to melanocytes and can inhibit tyrosinase. ${ }^{6}$ Imbalances in the oxidant/antioxidant system, such as the accumulation of hydrogen peroxide $\left(\mathrm{H}_{2} \mathrm{O}_{2}\right)$, increased level of malondialdehyde (MDA) and low catalase (CAT) levels, have recently been reported in the epidermis and blood of vitiligo patients. ${ }^{1,7-8}$

Antioxidants are body's defense mechanism against free radical damage. ${ }^{2}$ The oxidative stress can either result from increase generation or decreased destruction of free radicals. The level of antioxidant has been found to be decreased in vitiliginous skin. ${ }^{9}$ Hence reactive oxygen species are generated from the ultraviolet ray damaged epidermis. Zinc is one of the important trace elements related to health and disease. It is present in all cells and it's optimum concentration is required for the normal functions of cells, tissues and organs of the body. ${ }^{10}$ Zinc is considered as an antioxidant due to the dependency of the extracellular enzyme superoxide dismutase on zinc. ${ }^{9}$ Vitiligo patients also show reduced level of ascorbic acid. ${ }^{11-12}$ When folic acid, vitamin B12 and Vitamin $\mathrm{C}$ were administered orally for a long time, repigmentation was achieved without any side effect. ${ }^{11-13}$ Vitamin $\mathrm{C}$ is an essential nutrient for humans and certain other animal species. In living organisms, ascorbic acid also acts as an anti-oxidant, since it protects the body against oxidative stress. ${ }^{14}$

The purpose of this study was to evaluate the role of oxidative stress and antioxidant status in the pathogenesis of generalized and localized vitiligo. We therefore investigated the serum levels of MDA, $\mathrm{Zn}$ and Vit-C in vitiligo patients and in healthy controls. The correlation between these levels in vitiligo patients with their different sociodemographic factors was also investigated in the study.

\section{MATERIALS AND METHODS}

Subjects and study design. Thirty patients with vitiligo (10 males \& 20 females), age ranging from
14 to 50 years, were randomly recruited from the Department of Dermatology and Venereology, Bangabandhu Sheikh Mujib Medical University (BSMMU), Dhaka, Bangladesh. This was a type of case control study which was conducted during the period of September 2007 to July 2008. A specialist dermatologist conducted the diagnosis and interviewed the patients with vitiligo. The control group included 30 healthy individuals matched by age, sex, BMI, marital status, education, area of residence, and socio-economic status to the patient group, with no previous history of skin or autoimmune disorders.

A complete clinical examination was performed, and the site and pattern (generalized or localized) of the lesions were noted. The cases showing white patches due to secondary causes were excluded from this study. The study subjects were briefed about the purpose of the study and written consent was taken from each of them. A questionnaire form was filled up that contains personal information, socioeconomic data, history and current status of illness, family history etc. Investigators helped the subjects to fill up the form who had no formal education. Ethical approval was obtained from the Ethical Review Committee of Bangabandhu Sheikh Mujib Medical University Hospital (BSMMU), Dhaka, Bangladesh.

Blood sample collection. Ten $\mathrm{ml}$ venous blood sample was collected from the antecubital vein of each of the vitiligo patients and control subjects in a metal-free sterile tube, between 8 to 9 am after an overnight fasting. The blood was then allowed to clot at room temperature for 30 minutes and centrifuged for 15 minutes at $5000 \mathrm{rpm}$ to extract the serum. The serum was taken in eppendorf tube and stored at $-80^{\circ} \mathrm{C}$ for until analysis. Blood collection and serum separation were carried out in a dust-free environment. ${ }^{15}$

Determination of serum malondealdehyde (MDA). Serum MDA level, the indirect index of lipid peroxidation, was measured according to the modified method described by Satoh. ${ }^{16}$ Briefly, to 0.5 $\mathrm{ml}$ serum, $2.5 \mathrm{ml}$ of $20 \mathrm{mg} / \mathrm{dl}$ trichloroacetic acid was 
added and the tube was allowed to stand for $10 \mathrm{~min}$ at room temperature. After centrifugation at $3500 \mathrm{rpm}$ for $10 \mathrm{~min}$, the supernatant was decanted and the precipitate was washed once with $0.05 \mathrm{M}$ sulphuric acid. Then $2.5 \mathrm{ml}$ of $0.05 \mathrm{M}$ sulfuric acid and $3.0 \mathrm{ml}$ of $0.2 \mathrm{mg} / \mathrm{dl}$ TBA (in $2 \mathrm{M}$ sodium sulfate) were added to this precipitate and the coupling of lipid peroxide with TBA is carried out by heating in a boiling water bath for $30 \mathrm{~min}$. After cooling in cold water, the resulting chromogen was extracted with $4.0 \mathrm{ml}$ of n-butyl alcohol by vigorous shaking. Separation of the organic phase is facilitated by centrifugation at $3000 \mathrm{rpm}$ for $10 \mathrm{~min}$ and absorbance of the supernatant was measured spectrophotometrically (UV-1201 UV-VIS Spectrophotometer, Shimadzu Corporation, Japan) at $530 \mathrm{~nm}$ using 1,1,3,3-tetraethoxy-propane as standard. Thiobarbituric acid reactive substances (TBARS) were expressed as $\mu$. mole/L. ${ }^{15}$

Determination of zinc. The serum zinc level was measured by using flame atomic absorption spectrometry (Varian Spectra AA 220) at the Centre for Advanced Research in Sciences, University of Dhaka, Bangladesh. Different concentrations (0.5, $1.0,2.0,5.0$ and $10.0 \mathrm{mg} / \mathrm{L}$ ) of $\mathrm{Zn}$ were used for calibration of standard graph. Wavelength used was $213.9 \mathrm{~nm}$ and slit width was $0.7 \mathrm{~nm}$ for determining $\mathrm{Zn}$. A software package (Spectra AA software) was used to calculate concentrations of zinc. ${ }^{15}$

Determination of vitamin C. To analyze serum ascorbic acid, extracted serum was immediately treated with 5\% trichloroacetic acid (TCA) and centrifuged at $3000 \mathrm{rpm}$ for $10 \mathrm{~min}$. Clear supernatant thus obtained was stored at $-80^{\circ} \mathrm{C}$ for until analysis. The concentration of ascorbic acid was determined by UV-VIS spectrophotometer by using phenyl hydrazine as indicator as described by Islam et al. ${ }^{17}$ Absorbance was measured against a reagent blank at $520 \mathrm{~nm}$ by a UV-VIS Spectrophotometer (UV-1201, Shimadzu, Kyoto, Japan).

Statistical analysis. The SPSS software package (Version 14.0, SPSS Inc., Chicago, Illinois, USA) was used to analyze the data. Descriptive statistics were used for all variables. Data was presented as frequency, percentage, mean, and standard deviation. Comparison of MDA, Zn, and Vitamin C levels of patients and controls were performed by independent sample $t$-test. To determine the contribution of different socio-demographic factors and BMI on the concentration levels of MDA, Zn, and Vitamin C, independent sample student's $t$-test, Pearson's correlation analysis, multiple regression analysis and analysis of variance (ANOVA) were carried out. All comparisons were 2-tailed, and $p$ values of $<0.05$ were considered significant.

\section{RESULTS AND DISCUSSION}

Table 1 shows the socio-economic information of patients with vitiligo and control subjects. The mean (SD) age and BMI were 30.07 (11.09) years and 22.52 (3.07) $\mathrm{Kg} / \mathrm{m}^{2}$, respectively for Vitiligo patients. The biophysical characteristics of Vitiligo patients and control subjects are shown in Table 2.

The serum levels of MDA, vitamin $\mathrm{C}$ and zinc was presented in table 3. From statistical analysis, it was found that serum MDA increased significantly ( $p$ $<0.05)$ in Vitiligo patients compared to control subjects. Serum $\mathrm{Zn}$ level increased and serum ascorbic acid decreased in vitiligo patients when compared to control subjects but the changes were not statistically significant $(p>0.05)$. For regression analysis, the differences between serum levels of MDA, Zn and Vit-C, were considered as dependant variable \& socio-economic factors including age, BMI, income, occupation, education, and residence as independent variable. No significant relationship between these variables was observed. Effects of socio-demographic factors on serum levels of MDA, $\mathrm{Zn}$ and Vit-C were also analyzed by ANOVA. No significant relationship between these variables was observed at $5 \%$ level of significance $(p>0.05)$.

Vitiligo affects both the sex equally. ${ }^{3}$ However; socio-economic data of the vitiligo patients in the present study shows a female prevalence (66.67\%). Some previous study also supported this. ${ }^{18-19}$ The female predominance can be due to their more curiosity in cosmetics and frequent dermatologic 
consultations. The usual age of onset is between 10 and 30 years and it is generally accepted that almost half are under the age of $20 .^{3}$ In our study, 20 patients out of 30 was below the age of 30 . No significant relationship between the socioeconomic status and nutritional condition was observed at $5 \%$ level of significance $(p>0.05)$.

Table 1. Socio-demographic data of vitiligo patients $(n=30)$ and control subjects $(n=30)$.

\begin{tabular}{|c|c|c|c|c|c|c|}
\hline \multirow[t]{2}{*}{ Parameter } & \multicolumn{3}{|c|}{ Patients $(\mathrm{n}=30)$} & \multicolumn{3}{|c|}{ Control $(n=30)$} \\
\hline & $\mathrm{n}$ & $\%$ & Mean (SD) & $\mathrm{n}$ & $\%$ & Mean (SD) \\
\hline \multicolumn{7}{|l|}{ Education } \\
\hline Illiterate & 2 & 6.67 & & 4 & 13.33 & \\
\hline Can read only & 1 & 3.33 & & 2 & 6.67 & \\
\hline Secondary & 5 & 16.67 & & 4 & 13.33 & \\
\hline Higher secondary & 10 & 33.33 & & 4 & 13.33 & \\
\hline Graduate \& above & 12 & 40.0 & & 16 & 53.33 & \\
\hline \multicolumn{7}{|l|}{ Occupation } \\
\hline Service & 9 & 30.0 & & 16 & 53.33 & \\
\hline Business/worker & 3 & 10.0 & & 4 & 13.33 & \\
\hline Unemployed & 1 & 3.33 & & 0 & 0 & \\
\hline Housewife & 12 & 40.0 & & 8 & 26.67 & \\
\hline Others & 5 & 16.67 & & 2 & 6.67 & \\
\hline \multicolumn{7}{|l|}{ Monthly income in BDT ${ }^{*}$} \\
\hline $0-10000$ & 2 & 6.67 & & 5 & 16.67 & \\
\hline $10001-25000$ & 12 & 40.0 & 24375 & 13 & 43.33 & 23261 \\
\hline $25001-40000$ & 15 & 50.0 & (2073.03) & 12 & 40.0 & $(1560.65)$ \\
\hline$>40000$ & 1 & 3.33 & & 0 & 0 & \\
\hline \multicolumn{7}{|l|}{ Age in years } \\
\hline $14-20$ & 5 & 16.67 & \multirow{6}{*}{$\begin{array}{c}30.27 \\
(11.09)\end{array}$} & 5 & 16.67 & \multirow{6}{*}{$\begin{array}{c}32.27 \\
(11.08)\end{array}$} \\
\hline $21-25$ & 8 & 26.67 & & 8 & 26.67 & \\
\hline $26-30$ & 7 & 23.33 & & 11 & 36.67 & \\
\hline $31-40$ & 4 & 13.33 & & 4 & 13.33 & \\
\hline $41-50$ & 4 & 13.33 & & 1 & 3.33 & \\
\hline 51-60 & 2 & 6.67 & & 1 & 3.33 & \\
\hline \multicolumn{7}{|l|}{ Gender } \\
\hline Male & 10 & 33.33 & & 12 & 40.0 & \\
\hline Female & 20 & 66.67 & & 18 & 60.0 & \\
\hline \multicolumn{7}{|l|}{ Marital status } \\
\hline Married & 11 & 36.67 & & 26 & 86.67 & \\
\hline Unmarried & 19 & 63.33 & & 4 & 13.33 & \\
\hline \multicolumn{7}{|l|}{ Area of residence } \\
\hline Rural & 26 & 86.67 & & 28 & 93.34 & \\
\hline Urban & 3 & 10.0 & & 1 & 3.33 & \\
\hline Semi-Urban & 1 & 3.33 & & 1 & 3.33 & \\
\hline
\end{tabular}

${ }^{*}$ BDT=Bangladeshi Taka

In our study serum MDA level was found to be significantly higher in comparison with control subjects $(p<0.05)$. Our study result supports the findings of other investigations observed by others. ${ }^{1,8-11}$ Increased MDA represents increased lipid peroxidation i.e. enhanced free-radical-mediated processes. Free-radical reactions may be the chemical link between cell damage and the inflammatory response. ${ }^{15}$ Vitiligo is a common disease but, unfortunately, the pathogenesis of vitiligo is still unclear. Oxidative stress has been proposed as the triggering event in the melanocyte degeneration of Vitiligo. ${ }^{4-6}$ Lipoperoxidation, the primary reaction sites of which involves membrane-associated 
polyunsaturated fatty acids of phospholipids, can be considered a major manifestation of oxidative stress. $^{20}$

Serum ascorbic acid of vitiligo patients was found to be lower than the control but statistically insignificant $(p>0.05)$. Similar results were found in other studies. ${ }^{11-13}$ Due to the lower level of vitamin $\mathrm{C}$, free radicals may accumulate and contribute to the buildup of oxidative stress in the system. Vitamin $\mathrm{C}$ is called an antioxidant because, by donating its electrons, it prevents other compounds from being oxidized. ${ }^{14}$ Dietary vitamin-C consumption can lead to some stabilization and in some cases repigmentation. ${ }^{11}$

Table 2. Biophysical characteristics of vitiligo patients $(n=30)$ and controls $(n=30)$.

\begin{tabular}{ccccccc}
\hline \multirow{2}{*}{ Parameter } & \multicolumn{2}{c}{ Patients $(\mathrm{n}=30)$} & \multicolumn{3}{c}{ Control $(\mathrm{n}=30)$} \\
\cline { 2 - 6 } & $\mathbf{n}$ & $\mathbf{\%}$ & Mean (SD) & $\mathbf{n}$ & $\mathbf{\%}$ & Mean (SD) \\
\hline Height (m) & & & & & & \\
$1.31-1.50$ & 6 & 50 & 1.61 & 4 & 0 & 1.69 \\
$1.51-1.70$ & 23 & 50 & $(0.15)$ & 26 & 73.33 & $(0.87)$ \\
$1.71-1.90$ & 1 & 0 & & 0 & 26.67 & \\
\hline Weight (Kg) & & & & 7 & 20 & 57.23 \\
$35-50$ & 5 & 43.75 & 58.09 & 20 & 66.67 & $(7.25)$ \\
$51-66$ & 22 & 106.25 & $(11.28)$ & 3 & 13.33 & \\
$67-82$ & 3 & 12.5 & & & & \\
\hline BMI (Kg/m $\mathbf{2})$ & & & & 1 & 93.33 & 24.0 \\
$15.1-18.4$ & 6 & 43.75 & 22.52 & 22 & 73.33 \\
$18.5-25.0$ & 17 & 43.75 & $(3.07)$ & 7 & 0 & $(3.20)$ \\
$25.1-30.0$ & 7 & 12.5 & &
\end{tabular}

Normal human BMI ranges from 18.5-25 (Food and Agriculture Organization, 1994)

Table 3. Mean serum MDA, Vitamin C and Zn level of vitiligo patients $(n=30)$ and control subjects $(n=30)$.

\begin{tabular}{ccccc}
\hline & \multicolumn{4}{c}{ Mean \pm SD serum concentration } \\
\cline { 2 - 4 } & Patients & Control subjects & Reference value ${ }^{14,15,23}$ & $p$-value \\
\hline $\begin{array}{c}\text { MDA } \\
(\mu \mathrm{mol} / \mathrm{L})\end{array}$ & $2.60 \pm 1.12$ & $2.11 \pm 1.25$ & $<2.0$ & $0.015^{*}$ \\
$\begin{array}{c}\mathbf{V i t}-\mathbf{C} \\
(\mu \mathrm{mol} / \mathrm{L})\end{array}$ & $25.01 \pm 7.14$ & $25.94 \pm 7.98$ & $23-85$ & 0.694 \\
$\mathbf{Z n}$ & $1.08 \pm 0.07$ & $0.95 \pm 0.35$ & 0.85 & 0.250 \\
$(\mathbf{m g} / \mathbf{L})$ & &
\end{tabular}

Independent Sample $t$-test (2-tailed): *Significance $p<0.05$

Serum $\mathrm{Zn}$ level was found to be increased in the patients than controls, but the change was not statistically significant. Decreased serum zinc level was reported in number of cutaneous disorders by some investigators ${ }^{10,21-22}$, while others have refuted this finding. ${ }^{23-24} \mathrm{Zn}$ plays a vital role in the protection against free radical damage and takes part in the process of melanogenesis. Zinc catalyzes the rearrangement of dopachrome to form 5,6-dihydroxy indole-2'-carboxylic acid (DICA) in the process of melanogenesis. ${ }^{9}$

In conclusion, our study results definitely demonstrates an imbalance in the oxidant-antioxidant system in vitiligo patients compared to healthy control subjects which provides support for a free radical-mediated damage in the pathogenesis of vitiligo.

\section{REFERENCES}

1. Jain, D., Misra, R., Kumar, A. and Jaiswal, G. 2008. Levels of malondialdehyde and antioxidants in the blood of patients with vitiligo of age group 11-20 years. Indian J. Physiol. Pharmacol. 52, 297-301.

2. Handa, S. and Kaur, I. 1999. Vitiligo: Clinical findings in 1436 patients. J. Dermatol. 26, 653-657. 
3. Mosher, D.B., Fitzpatrick, T.B. and Ortanne, J.B. 1999. Disorders of pigmentation, hipomelanoses and hypermelanoses. Dermatol. Gen. Med. 5, 936-945.

4. Onganae, K. and Van, Geel. 2003. Evidence for an autoimmune pathogenesis of vitiligo. Pigment Cell Res. 16, 90-100.

5. Cross, C.C., Halliwell, B., Borish, et al. 1987. Davis conference: oxygen radicals and human disease. Ann. Intern. Med. 107, 536-545.

6. Jaynath, D.P., Pai, B.S., Shenoi, S.D. and Balachandran, C. 2002. Efficacy of antioxidants as an adjunct to photochemotherapy in vitiligo. A case study of 30 patients. Indian J. Dermatol. Venereol. Leprol. 68, 202-205.

7. Schallreuter, K.U., Moore, J., Wood, J.M., et al. 2001. Epidermal $\mathrm{H}_{2} \mathrm{O}_{2}$ accumulation alters tetrahyrobiopterin (6BH4) recycling in vitiligo: Identification of general mechanism in regulation of all 6BH4-dependent processes? J. Invest. Dermatol. 116: 167-74.

8. Schallreuter, K.U., Moore, J., Wood, J.M., et al. 1999. In vivo and in vitro evidence for hydrogen peroxide $\left(\mathrm{H}_{2} \mathrm{O}_{2}\right)$ accumulation in the epidermis of patients with vitiligo and its successful removal by a UVB-activated pseudo catalase. $J$. Invest. Dermatol. 4, 91-96.

9. Shameer, P., Prashad, P.V.S, and Kaviarasan, P.K. 2005. Serum zinc level in vitiligo: a case control study. Indian $J$. Dermatol. Venereol. Leprol. 71, 206-207.

10. Arora, P.N., Dhillon, K.S., Rajan, S.R., Sayal, S.K. and Das, A.L. Serum zinc levels in cutaneous disorders. MJAFI; 58, 304-306.

11. Montes, L.F., Diaz, M.L., Lajous, J. and Garcia, N.J. 1992. Folic acid and vitamin B12 in vitiligo: a nutritional approach. Cutis. 50, 39-42.

12. Khan, R., Satyam, A., Gupta, S., Sharma, V.K. and Sharma, A. 2009. Circulatory levels of antioxidants and lipid peroxidation in Indian patients with generalized and localized vitiligo. Archives of Dermatological Res. 301, 731-737.

13. Juhlin, L. and Olsson, M.J. 1997. Improvement of vitiligo after oral treatment with vitamin B12 and folic acid and the importance of sun exposure. Acta. Derm. Venereol. 77, 460462.

14. Padayatty, S.J., Katz, A., Wang, Y., Kwon, O,, Leem J,H,, Chenm S, et al. 2003. Vitamin $\mathrm{C}$ as an Antioxidant: Evaluation of its role in disease prevention, J. Am. Coll. Nutr. 22, 19-35.
15. Mannan, S.J., Azad, M.A.K., Ullah, M.A., Maruf, A.A., Rayhan, M.I., Ahsan, M.S. and Hasnat, A. 2010. Investigation of serum trace element, malondialdehyde and immune status in drug abuser patients undergoing detoxification. Biol. Trace. Elem. Res. Apr 14, [Epub ahead of print].

16. Satoh, K. 1978. Serum lipid peroxide in cerebrovascular disorders determined by a new colorimetric method. Clin. Chim. Acta. 90, 37-43.

17. Islam, S.N., Hossain, K.J. and Ahsan, M. 2001. Original Communication: Serum vitamin E, C and A status of the drug addicts undergoing detoxification: influence of drug habit, sexual practice and lifestyle factors. Eur. J. Clin. Nutr. 55, 1022-1027.

18. Akrem, J., Baroudi, A., Aichi, T., Houch, F. and Hamdaoui, M.H.2008. Profile of vitiligo in the south of Tunisia. Int. J. Dermatol. 47, 670-674

19. Martis, J., Bhat, R., Nandakishore, B. and Shetty, J.N. 2002. A clinical study of vitiligo. Indian. J. Dermatol. Venereol. Leprol. 68, 92-93.

20. Jimbow, K., Chen, H., Park, S. and Thomas, P.D. 2001. Increased sensitivity of melanocytes to oxidative stress and abnormal expression of trosinase-related protein in vitiligo. Br J Dermatol. 144, 55-65.

21. Tasake, M., Hanada, K. and Hashimoto, I. 1993. Analysis of serum copper and zinc levels and copper/zinc ratio in skin diseases. J. Dermatol. 20, 21-24.

22. Arora, B.P.N., DhilIon, M.K.S., Rajan, S.R., Sayal, S.K. and Das, A.L. 2002. Serum zinc levels in cutaneous disorders. MJAFI. 58, 304-306.

23. Kreft, B., Wohlrab, J., Fischer, M., Uhlig, H., Skolziger, R. and Marsch, W.C. 2000. Analysis of serum zinc levels in patients with atopic dermatitis, psoriasis vulgaris and probands with healthy skin. Hautarzt. 51, 931-934.

24. Ozturh, G., Erbas, D., Gelir, E., Gulekon, A. and Imir, T. 2001. Natural killer cells activity, serum immunoglobulins, complement protein and zinc level in patient with psoriasis vulgaris. Immunol. Invest. 30, 181-190. 